Artículos Cientificos

\title{
Insuficiencia habitacional y Programa "Minha Casa Minha Vida" en pequeñas ciudades de la Amazonía Paraense-Brasil
}

\author{
Housing inadequacy and Programa "Minha Casa \\ Minha Vida" in small cities in the Paraense Amazon- \\ Brazil
}

\section{Inadequação habitacional e Programa "Minha Casa Minha Vida" em pequenas cidades na Amazônia Paraense-Brasil}

\author{
Mônica de Melo Medeiros \\ Trabajadora social. Alumna de doctorado del Programa de Posgrado en Trabajo Social de la Universidad Federal de Parál UFPA. \\ Miembro del Grupo de Estudio e Investigación Ciudad, Vivienda y Espacio Humano. Belém-Brasil \\ Correo electrónico: monica.melom@yahoo.com.br \\ https://orcid.org/0000-0002-5602-3661

\section{Joana Valente Santana} \\ Trabajadora social. Doctora en Trabajo Social de la Universidad Federal de Rio de Janeiro/UFRJ. Profesora de la Facultad de \\ Trabajo Social e del Programa de Posgrado em Trabajo Social de la Universidad Federal de Pará/UFPA. Coordinadora del Grupo \\ de Estudio e Investigación Ciudad, Vivienda y Espacio Humano. Belém-Brasil \\ Autor de correspondencia: joanavalente@ufpa.br \\ https://orcid.org/0000-0003-4033-1317
}

\begin{abstract}
Resumen
Este artículo tiene como objetivo analizar el grado en que la insuficiencia habitacional por falta de infraestructura urbana es superada a través del Programa "Minha Casa Minha Vida" (PMCMV) en el Estado de Pará/Brasil. La investigación se guía por el método del materialismo histórico-dialéctico y la metodologia se basó en investigaciones bibliográficas, documentales y investigación en proyectos de vivienda en dos ciudades de Pará (Tomé-Açu y Benevides) para captar la condición de vivienda de dos proyectos de PMCMV, con 402 y 360 unidades de vivienda, respectivamente. Los hallazgos de la investigación indican que el programa de vivienda construye hogares inadecuados, es decir, separados de las necesidades de vivienda de los sujetos que tienen particularidades regionales en la manera de vivir. El programa habitacional permite a las familias mejoras relacionadas con el acceso a su propia vivienda y la eliminación de los costos de alquiler. Por otro lado, se pueden citar cómo puntos negativos la falta de acceso a la infraestructura urbana, movilidad, seguridad, aumento del costo de vida, desarticulación de estrategias de supervivencia, falta de habitaciones más grandes y ventiladas, así como las condiciones para realizar reparaciones en la estructura interna y externa de la casa (con destaque para el alcantarillado y la cocina), revelando la contradicción de la política de vivienda al no superar la insuficiencia habitacional por falta de infraestructura urbana.

Palabras clave: Insuficiencia habitacional, derecho a la vivienda, vivienda adecuada, vivienda en la Amazonía, PMCMV.
\end{abstract}




\begin{abstract}
This article has the purpose of analyse to what extent housing inadequacy due to lack of urban infrastructure is overcome through the Programa Minha Casa Minha Vida (PMCMV) in the State of Pará/Brazil. The research is guided by the method of historical and dialectical materialism and the methodology was based on bibliographic, documental and field research in two cities in Pará (Tomé-Açu and Benevides) to apprehend the housing condition of two PMCMV projects, with 402 and 360 housing units, respectively. The research results show that the housing program builds inadequate homes, in other words, unrelated to the housing needs of individuals who have regional particularities in their way of living. The housing program provides the families improvements related to access to their own home and the elimination of rent costs on the other hand, the lack of access to urban infrastructure, mobility, security, increased cost of living, disarticulation of survival strategies, lack of larger and airy rooms, in addition to conditions of carrying out repairs to the internal and external structure of the house (highlighting on the sanitary sewage and kitchen), revealing the contradiction of the housing policy by not overcoming the housing inadequacy due to lack of urban infrastructure.
\end{abstract}

Keywords: Housing inadequacy, right to housing, proper housing, housing on Amazon, PMCMV.

\title{
Resumo
}

0 presente artigo tem como objetivo analisar em que medida a inadequação habitacional por carência de infraestrutura urbana é superada por meio do Programa Minha Casa Minha Vida (PMCMV) no Estado do Pará/Brasil. A pesquisa orienta-se pelo método do materialismo histórico e dialético e a metodologia baseou-se em levantamento bibliográfico, documental e pesquisa de campo em duas cidades paraenses (Tomé-Açu e Benevides) para apreender a condição de moradia de dois empreendimentos do PMCMV, com 402 e 360 unidades habitacionais, respectivamente. Os resultados da pesquisa apontam que o programa habitacional constrói domicilios inadequados, ou seja, desvinculados das necessidades de moradia dos sujeitos que possuem particularidades regionais no modo de morar. 0 programa habitacional possibilita às familias melhorias relacionadas ao acesso a casa própria e eliminação dos custos com aluguel, por outro lado, destaca-se como pontos negativos a falta de acesso à infraestrutura urbana, mobilidade, segurança, aumento do custo de vida, desarticulação das estratégias de sobrevivência, carência de cômodos maiores e arejados, além de condições para realizar reparos na estrutura interna e externa da casa (destaque para o esgotamento sanitário e cozinha), revelando a contradição da política habitacional ao não superar a inadequação habitacional por carência de infraestrutura urbana.

Palavras-chaves: Inadequação habitacional, direito à moradia, moradia adequada, moradia na Amazônia, PMCMV.

\section{lntroducción}

Este artículo presenta los hallazgos de la investigación, ${ }^{1}$ que se detuvo en analizar la medida en que la provisión de vivienda a través del Programa "Minha Casa Minha Vida" (PMCMV) contribuye a superar la insuficiencia habitacional por infraestructura urbana en las pequeñas ciudades de Pará, particularmente en los municipios de Benevides y Tomé-Açu. Se propone presentar, en cierta medida, cómo el Programa tiene brechas que impiden la garantía de soluciones habitacionales con acceso a infraestructura urbana.
Brasil es un país que lleva el sello de una historia de explotación de la fuerza laboral y expropiación de la naturaleza, esclavitud humana de las personas negras, falta de respeto y mortandad de las comunidades tradicionales y pueblos, patriarcado y el desprecio por las mujeres y las personas LGBTQIA +. Las marcas de su historia manifiestan las diversas etapas de expansión de la economía capitalista, que está configurando una división del trabajo en que la desigualdad de clases se expresa en la producción del espacio urbano y rural.

1 Proyecto de investigación que se inserta en el Grupo de Estudio e Investigación Ciudad, Vivienda y Espacio Humano (GEP-CIHAB), vinculado al Programa de Posgrado en Trabajo Social /PPGSS, de la Universidad Federal de Pará/Brasil. La investigación se realizó con una Beca de Maestría financiada por la Coordinación de Perfeccionamiento del Personal de Educación Superior /Capes Ministerio de Educación /Brasil. 
Entre las diversas expresiones de desigualdad social y económica en Brasil, el tema de la vivienda - considerado una expresión de la cuestión social - revela la disparidad en el acceso a los bienes producidos en la ciudad por las diversas fracciones de clase. La falta de infraestructura (falta de suministro de agua y/o solución de alcantarillado y/o electricidad y/o recolección de basura), uno de los componentes de la insuficiencia habitacional, es una realidad en varios hogares de Brasil.

La insuficiencia habitacional no está directamente relacionada con la falta de unidades habitacionales, está relacionada con problemas que producen malas condiciones de vida y afectan la calidad de vida de la población. El conjunto de necesidades que se constituyen como insuficiencia habitacional son la irregularidad del suelo, la falta de suministro de agua y alcantarillado sanitario, la densidad excesiva, la falta de infraestructura urbana, la falta de recolección de basura y distribución de energía eléctrica (Sakatauskas, 2015). Las principales variables de insuficiencia habitacional son: a) hogares con falta de infraestructura (ausencia de suministro de agua y/o solución de alcantarillado sanitario y / o electricidad y / o recolección de basura); b) hogares con excesiva densidad de residentes (más de tres residentes por dormitorio); c) hogares sin unidad de salud exclusiva; d) hogares con problemas de irregularidad del suelo (Santana, 2016).

Con base en datos del IBGE (2019), Santana y Ferreira (2021) destacan que, para el año 2018, las peores tasas de escasez de infraestructura en Brasil se presentaron en hogares donde residen personas con ingreso familiar per cápita inferior a US\$ 5,50 PPC diarios, "y la dificultad de acceso al alcantarillado en esta población es bastante alta, alcanzando un número expresivo de 56,2\%” (p. 135). Además, siguiendo el proceso de desigualdad socio-territorial en el país, la región Norte ${ }^{2}$ tiene las peores tasas referidas a la proporción de la población que vive en hogares sin servicios de saneamiento, porque en esta región, "la ausencia de alcantarillad llega al 79,3\% de los hogares" (p. 138).

De entre los estados de la Región Norte, Santana y Holanda (2016) basados en el Plan Estatal de Vivienda (PEHIS/2014) muestran que el estado de Pará es expresivo en cuanto a la ausencia de infraestructura, ya que entre 2000 y 2010 hubo una tendencia de crecimiento del $46 \%$ de esta carencia, datos absolutamente mediados por la desigualdad socioeconómica, puesto que para el año 2020, en todas las regiones de integración de este estado, la pobreza extrema representa alrededor del $50 \%$ de la población pobre.

\section{Metodología}

Considerando la realidad nacional y del Estado de Pará, la reflexión propuesta en este artículo es investigar cómo la implementación del Programa "Minha Casa Minha Vida" en dos pequeñas ciudades del estado de Pará se refleja en la reproducción de la vida de trabajadores de bajos ingresos, especialmente con respecto al impacto en el tema de la insuficiencia habitacional por infraestructura urbana.

La investigación se llevó a cabo a partir del método del materialismo histórico y dialéctico sintetizado por Karl Marx, un método que permite la interpretación e indica la necesaria superación del orden burgués ${ }^{3}$. El desarrollo metodológico de la investigación consistió en investiga-

2 La región Norte comprende una división geopolítica de Brasil, compuesta por los Estados de Acre (AC), Amapá (AP), Amazonas (AM), Pará (PA), Rondônia (RO), Roraima (RR) y Tocantins (TO). Con un clima ecuatorial, limita con Bolivia, Perú, Colombia, Venezuela, Guyana, Surinam y Guayana Francesa. Escala 1:2.700.000/ Meridiano de Referencia: -59 45’ y Referencia Paralela: -4 15’ (IBGE, 2017).

3 El método marxiano permite "[...] captar y articular - a través de la racionalidad dialéctica - que aparentemente está desorganizada o fragmentada, es decir., [...] captar las mediaciones contradictorias que existen en la realidad y que están vinculadas a la dominación de clase. Es fundamental referirse a la totalidad histórica, frente a las mistificaciones teóricas que colocan la centralización de la producción de conocimiento, ya sea en el sujeto o en el objeto, en claro empobrecimiento de la razón, utilizando la expresión de Coutinho (2010)". (Ferreira y Santana, 2018, p. 81, grifos en el original, traducción propia). 
ción bibliográficas ${ }^{4}$, documentales y de investigación en proyectos de vivienda $a^{5}$ en las ciudades de Benevides y Tomé-Açu, en el estado de Pará (ubicado en el norte de Brasil), que recibieron el PMCMV- Sector 01, así como tienen altas tasas de insuficiencia habitacional ${ }^{6}$.

Esta investigación llegó a 110 sujetos $^{7}$ mediante la aplicación de un formulario de investigación que contiene información sobre la persona residente, el trabajo y los ingresos, la situación de la vivienda, la situación de los servicios públicos, la participación política de la familia, los impactos de la financiación y la percepción del residente sobre las condiciones de la vivienda. En el municipio de Tomé-Açu, de un total de 402 unidades habitacionales/UH, se aplicaron 54 formularios y en el municipio de Benevides, de un total de $360 \mathrm{UH}$, se aplicaron 53. Además, se realizaron 13 entrevistas basadas en un guion semiestructurado y se entrevistó en Benevides a 05 residentes y 02 técnicos de la alcaldía (ingeniero civil y socióloga); y en Tomé-Açu, 05 residentes y 01 técnico de la alcaldía (Trabajador Social).

Con base en el concepto de espacio en Santos (2014), se realizó una observación de los espacios destinados a la producción de viviendas a través de las variables: a) acceso al área, b) red de servicios públicos, c) caracterización del área, considerando que la visita a los complejos habitacionales se realizó en los turnos de mañana, tarde y noche y en diferentes días de la semana para alcanzar un mayor número de determinantes en la observación y análisis del espacio.

En este marco, este trabajo tiene como objetivo analizar el grado en que la insuficiencia habitacional por falta de infraestructura urbana es superada a través del Programa "Minha Casa Minha Vida" (PMCMV) en el Estado de Pará/Brasil. Las variables investigativas de las entrevistas fueron: a) analizar la inadecuación habitacional en pequeñas ciudades; b) evaluar en qué medida la inversión en vivienda contribuye a mejorar los indicadores de adecuación de la vivienda por infraestructura; c) analizar cómo se realiza el abastecimiento de agua y alcantarillado, alumbrado público y recolección de basura, además de la cobertura de los servicios públicos como componentes de vivienda inadecuada en los proyectos del PMCMV; d) analizar si hay repercusiones del financiamiento de la vivienda en la reproducción de la vida de la clase trabajadora de bajos ingresos; e) analizar cómo es la comprensión

4 La investigación bibliográfica buscó conocer y analizar aportes sobre la política de vivienda como la realización de un conjunto de derechos sociales, incluido el acceso a la infraestructura urbana. Por ello, se llevó a cabo a) la selección y lectura de disertaciones y tesis de la Coordinación para la mejora del Personal de Educación Superior (CAPES), que sustentaron la elaboración del proyecto de investigación y que contribuyeron a la interpretación de la realidad estudiada y construcción de las categorías que surgieron de la investigación; b) busca de artículos en el Portal de Revistas de la Coordinación para la mejora del personal de nivel (CAPES), que discuten el tema en estudio y c) lectura de los trabajos producidos por el Grupo de Estudio e Investigación Ciudad, Vivienda y Espacio Humano (GEP-CIHAB) ). Para una primera aproximación se realizó una investigación exploratoria, en el Catálogo de Tesis y Disertaciones de CAPES, disponible en el siguiente sitio web: $<$ https://catalogodeteses.capes.gov.br/catalogo-teses/\#! I>, en el que se incluyeron los trabajos encontrados en la plataforma hasta noviembre de 2018 con el fin de incluir estudios más actuales. Para ello, se investigaron cuatro grupos de palabras clave. Se seleccionaron trabajos de maestría y doctorado en el campo de las Ciencias Sociales Aplicadas. a) GRUPO 01: "financiarización de la vivienda"; b) GRUPO 02: "precariedad habitacional", "vivienda inadecuada", "necesidades habitacionales" y "escasez habitacional"; c) GRUPO 03: Programa Minha Casa Minha Vida y d) GRUPO 04: "Vivienda en la Amazonía" y "Pequeñas ciudades". Del universo investigado se leyeron los resúmenes de los trabajos y se seleccionaron los más acordes con el tema de investigación. Los trabajos seleccionados se tabularon en una tabla en Word y se organizaron, eliminando en un primer momento la información relativa al universo encontrado, título del trabajo, autor, año, posgrado, resumen y tipo de trabajo (maestría o doctorado). Posteriormente, se leyeron y analizaron un total de 23 (veintitrés) trabajos y 32 (treinta y dos) artículos y capitulos de libros producidos por GEP-CIHAB.

5 La investigación se realizó de mayo a agosto de 2019. En aproximación a la investigación se establecieron contactos con las autoridades municipales, así como se entregaron cartas de invitación a la comunidad residente informando sobre la aplicación de los formularios y entrevistas, que fueron autorizados mediante la firma del Término de Consentimiento Libre y Esclarecido (TCLE), y se preservó la identidad de las personas investigadas. Cabe destacar que la investigación fue presentada a la Plataforma Brasil y al Comité de Ética en Investigación de la UFPA, obteniendo la aprobación a través del Certificado de Presentación para la Apreciación Ética (CAAE): 13995819.4.0000.0018, opinión num. 3.526.144

6 La modalidad del PMCMV Urbano-SECTOR 01 es destinada a las familias con ingreso mensual de hasta R $\$ 1.800,00$ (Un mil y ochocientos reales). Su fuente de recursos es el Fondo de Arrendamiento Residencial (FAR) a partir del cual es posible obtener hasta $90 \%$ de subsidio del valor del inmueble y el financiamiento es realizado en hasta 120 prestaciones mensuales en el valor máximo de $R \$ 270,00$, sin interés.

7 De entre el total de 107 residentes que respondieron a los formularios de investigación, fueron seleccionados 10 (05 de cada municipio) para la concesión de entrevista semiestructurada, además de 03 técnicos de las alcaldías. Hay, así, 110 sujetos participantes de la investigación. 
de las personas residentes sobre la inadecuación de la vivienda en el PMCMV.

En mayo de 2019 se realizó el primer contacto con el municipio de Tomé-Açu, con el objetivo de conocer el área de investigación y entregar invitaciones a las personas residentes. Se entregaron 100 invitaciones en Residencial Nova Esperança (Ipitinga) para la presentación de la investigadora y la investigación. Las entrevistas y la aplicación de los formularios se realizaron entre mayo y junio de 2019. En la ciudad de Benevides, el abordaje se llevó a cabo en junio y julio de 2019 con la entrega de 60 (sesenta) invitaciones, y las entrevistas y aplicación de los formularios se realizaron en julio de 2019. También se contactó vía telefónica y correo electrónico con las secretarías municipales y se solicitó a la Secretaría del Programa de Posgrado en Trabajo Social preparar cartas oficiales para informar a la administración municipal del período de realización de la investigación, sus objetivos, presentación del investigador y la programación. La carta fue entregada a la Secretaría Municipal de Asistencia Social (SETAS) de Tomé-Açu en mayo de 2019 y a la Secretaría Municipal de Vivienda de Benevides en junio de 2019. Es importante destacar que el abordaje de campo fue intencional antes de entregar el oficio a los ayuntamientos para intentar acercarnos a las relaciones sociales en los conjuntos habitacionales sin correr el riesgo de posibles injerencias de las administraciones. Los sujetos que estuvieron dispuestos a conceder una entrevista autorizaron la grabación de audio firmando el Término de Consentimiento Informado, preservando el anonimato. Las entrevistas fueron grabadas y transcritas. Después los datos fueron organizados en una tabla de Excel según el guion de la entrevista, sistematizados y, finalmente, resumidos los resultados.

La primera sección de los resultados presenta la propuesta para la operabilidad del Programa "Minha Casa Minha Vida" (PMCMV). La segunda presenta los datos relacionados con la investigación sobre la insuficiencia habitacional por infraestructura en los municipios investigados vinculada a la discusión sobre necesidades de vivienda y particularidades en la forma de vivir en la Amazonía de Pará. Por último, se presentan las consideraciones finales.

\section{Resultados y Discusión}

\section{Problema de Vivienda y Programa "Minha Casa Minha Vida"}

Las ciudades, ya sean grandes, medianas o pequeñas, tienen elementos universales y, al mismo tiempo, singulares; elementos que pueden ser incautados en particularidad histórica y en diferentes lugares. La literatura de base marxista demuestra que la ciudad capitalista es constituyente y constituida por relaciones sociales burguesas, que tienen su génesis y desarrollo a partir del proceso de industrialización, cuando el modo de producción capitalista requiere un modo de vida urbano, que difería del modo de producción anterior (el modo feudal de producción). Así, las ciudades que se constituyen en el orden burgués expresan la desigualdad económica y social propia del nuevo modo de producción, es decir, expresa la desigualdad de clase: trabajadores desprovistos de los medios de producción venden su fuerza de trabajo al capitalista, produciendo riqueza social, que es apropiada individualmente por los capitalistas.

En esta relación contradictoria, los bajos salarios percibidos no permiten a la clase de trabajadores adquirir la mercancía de la vivienda y, por lo tanto, el cumplimiento de esta necesidad humana básica (vivienda), se lleva a cabo en niveles inadecuados y con falta de infraestructura. Debido a estos límites, la vivienda se convierte en una

"mercancía imposible" para grandes porciones de trabajadores. Estas limitaciones y restricciones en Brasil se han vuelto más estrechas de las políticas neoliberales adoptadas por el gobierno central, cuyo ejemplo más evidente es en la reducción del gasto social frente a la asignación de grandes sumas de recursos públicos para el saneamiento de los bancos (Ramos \& Sá, 2002, p. 154).

La respuesta del Estado burgués a la demanda de vivienda de clase trabajadora ha sido históricamente la implementación de políticas que sirven prioritariamente a los intereses privados, especialmente los intereses del mercado inmobiliario, ${ }^{8}$ como las respuestas hechas por el

8 Al límite de las páginas del artículo, no es posible desarrollar los fundamentos de la producción de la ciudad capitalista. Se observa, sin embargo, que la orientación teórica de la investigación sigue las discusiones llevadas a cabo por Engels (2008, 2015), Marx (2013), Harvey (2005), Santos (2014), entre otros. 
Estado brasileño en relación con el tema de la vivienda, que prácticamente no enfrentó - ni pudo enfrentar - la resolución de los problemas de vivienda.

En este contexto, la vivienda es un concepto en disputa, donde se opone el concepto de derecho social fundamental, básico para la supervivencia y el acceso a los servicios de la ciudad, o un bien de consumo individual, una mercancía, un activo financiero. Para el capital, representado por el sector de la construcción y el mercado inmobiliario, la política de vivienda es un nicho de mercado para satisfacer sus intereses (Paz et al., 2018, p.111).

En el contexto de las disputas sobre el acceso a la vivienda, la historia de Brasil registra la lucha por el derecho a la ciudad, expresada en los logros que pueden resumirse en torno a la aprobación del Estatuto de la Ciudad (Ley Federal 10.257/2001), la creación del Ministerio de las Ciudades ${ }^{9}$ en 2003, las directrices de la Política Nacional de Vivienda y el Sistema Nacional de Vivienda de Interés Social $\left(\mathrm{SNHIS}^{10}\right.$ ), que tenían como premisa, en general, la gestión democrática de las ciudades y la producción de viviendas dirigidas a la clase trabajadora. Si bien, durante el periodo de gobierno del Partido de los Trabajadores (2003 a 2016), hubo importantes logros con relación a la vivienda de interés social, predominó la lógica de la vivienda de mercado, como el Programa "Minha Casa Minha Vida" (PMCMV).

El PMCMV fue creado en 2009 como una medida anticrisis en articulación de la Casa Civil con el Ministerio de Hacienda, en diálogo directo con los sectores inmobiliario y de la construcción civil. Estaba dirigi- do a la atención de familias con ingresos mensuales de hasta 10 salarios mínimos, con acceso restringido a empresas del sector de la construcción civil, en las que el gobierno pudiera participar en la provisión de áreas, infraestructura y otras acciones facilitadoras (Cardoso \& Aragão 2013; Arantes \& Fix, 2009).

En el segundo semestre de 2008, se producen nuevos cambios en respuesta a la crisis mundial de la economía brasileña: el gobierno brasileño trató de mitigar sus efectos internos mediante la adopción de políticas keynesianas que incluían el mantenimiento del crédito, el servicio a los sectores más afectados por la recesión y el apoyo a las inversiones públicas, particularmente en el área de infraestructura, que ya había sido objeto del Programa de Aceleración del Crecimiento (PAC). En el marco de estas medidas, se destacó el "paquete" de inversiones puestas en marcha para el área de vivienda. En marzo de 2009, con el objetivo de crear las condiciones para ampliar el mercado de la vivienda para atender a las familias con ingresos de hasta 10 salarios mínimos (SM), el gobierno anuncia el Programa "Minha Casa Minha Vida" (PMCMV). (Cardoso, Aragão, Araújo, 2011, p. 04).

Se considera que la modalidad de PMCMV/Sector 1 - dirigida a atender a las familias con ingresos de 0 a tres salarios mínimos donde el beneficiario paga 120 (ciento veinte) cuotas correspondientes al 10\% de los ingresos declarados - es una de las estrategias de producción de vivienda de lógica financiada ${ }^{11}$.

Los autores que se propusieron analizar el PMCMV enumeran una serie de problemas en la implemen-

9 En 2019, en el período posterior al golpe de Estado en Brasil, el gobierno del presidente Jair Bolsonaro extinguió el Ministerio de las Ciudades y lo fusionó con el Ministerio de Integración Nacional, creando el Ministerio de Desarrollo Regional.

10 "La lógica de la creación del Sistema Nacional de Vivienda de Interés Social sería fortalecer los organismos públicos municipales y estatales para la implementación de políticas de vivienda. Los fondos de HIS serían los mecanismos que permitirían a los municipios apalancar sus propios recursos y aprovechar los recursos federales o estatales que les serían repasados. Al mismo tiempo, los Consejos de Gestión de los Fondos locales promoverían una mayor participación de la sociedad civil en relación con la definición de la asignación y el uso de los recursos aportados para el HIS. El fortalecimiento de la esfera estatal local indicó la necesidad de la construcción de una nueva cultura política y de nuevos mecanismos institucionales para las acciones de política urbana y de vivienda". (Cardoso y Aragão, 2013, p. 32).

11 La financiación no solo se refiere a un procedimiento de capitalización adoptado por las empresas del sector inmobiliario, también es una racionalidad que se revela en la vida cotidiana de la producción capitalista. Además del proceso de recaudación de fondos a través de la concesión de créditos y el retorno en forma de interés, también tiene poder ideológico basado en valores abstractos que sirven como instrumentos de control (SHIMBO, 2010). Esta nueva versión del capitalismo en la era de la hegemonía de las finanzas y el capital ficticio tiene un creciente dominio de los actores, los mercados y el propio Estado (Rolnik, 2015). 
tación del Programa, entre ellos, la dificultad de su gestión por parte de los gobiernos municipales.

Los proyectos no son formulados por el gobierno ni por demanda organizada, no son licitados, no están definidos como parte de la estrategia municipal de desarrollo urbano y han sido contradichos. Están diseñados estrictamente como bienes, rentables para sus defensores [...] Los municipios no juegan un papel activo en el proceso, salvo en la exigencia de que se cumpla la legislación local, el sumo, el chalet presentado por Caixa Económica se puede proponer a través de él. contratación de códigos de trabajo y legislación municipal en varias ciudades, generando impasses. No fortalecimiento de estructuras de gestión municipal, proyectos y control de uso del suelo. Corresponde al público local decidir dónde invertir, definir la calidad de los proyectos y realizar las licitaciones de las obras. También es probable que los municipios estén bajo presión, en ciudades medianas (más de 50 mil habitantes, y que son el principal objetivo de la embestida), para cambiar la legislación de ordenamiento territorial, los coeficientes de aprovechamiento e incluso el perímetro urbano, para hacer los proyectos económicamente viables. Las empresas de vivienda y los departamentos de vivienda deben estar preparados para convertirse en un contador de "aprobaciones" muchas de las "flexibles" (Arantes y Fix, 2009, p. S / n).

Además, considerando la lógica de mercado contenida en el Programa, el PMCMV se ha alejado de las prerrogativas de vivienda de interés social. Como demuestran Cardoso y Jaenisch (2014, p. 156, traducción propia): “(...) El responsable de la producción es la iniciativa privada, que hace uso de una serie de estrategias para reducir el costo y permitir la producción dentro del valor máximo por unidad de vivienda". Una de las consecuencias de la lógica de comercialización del programa es la construcción de unidades habitacionales en lugares alejados de los servicios de infraestructura urbana, como se verá en el siguiente punto, cuando se presentarán los resultados de la investigación en ciudades de Pará (Benevides y Tomé-Açu).

Todo este proceso terminó por "retirar al Estado como proveedor directo de vivienda popular y establecerlo o acceder a él desde una relación de consumo" (ARAGÃO, 2015, p. 08). Estos mecanismos forman la globalización de las finanzas en las ciudades. Así, el patrón de acumulación del urbanismo en la ciudad capitalista es responsable por acuerdos y contratos que abarataban la propiedad de la vivienda. Sin embargo, la producción masiva de unidades de vivienda está relacionada con la periferización y segregación espacial de las personas beneficiarias de los programas de vivienda.

\section{Insuficiencia habitacional para infraestructura urbana en proyectos del PMCMV-Benevides y Tomé-Açu}

La expansión de PMCMV Sector 01 tiene una concentración significativa de unidades habitacionales (UH) en municipios de hasta 100.000 habitantes en el Estado de Pará, totalizando la producción de $35.529 \mathrm{UH}$. Este número es cercano a la producción de UH dirigida a municipios con 100.001 habitantes o más, totalizándose 40.287 , evidenciando la expansión del programa a ciudades pequeñas y medianas (CAIXA, 2019). Según la Fundación João Pinheiro, el Estado de Pará, en 2018, tenía 415.344 hogares urbanos duraderos con al menos un tipo de carencia de infraestructura. Esto significa que el número de unidades habitacionales producidas en todo el estado alcanza solo el $18 \%$ de esta variable de insuficiencia habitacional.

[...] hubo un aumento expresivo en lo que se refiere a la insuficiencia debido a la falta de infraestructura. Las Regiones de Integración donde el aumento de la escasez de infraestructura fue más significativo fueron precisamente las regiones que tuvieron mayor incremento del PIB, y que presentan actividades económicas relacionadas con la exploración mineral (Araguaia, Carajás y Tocantins). Estos datos son muy relevantes, ya que la expansión de la infraestructura es una acción de responsabilidad del Estado e incluso con la expansión del ingreso económico en estas regiones y en Pará, las inversiones en infraestructura se han quedado cortas, agravando el problema de la vivienda del territorio de Pará (Santana \& Holanda, 2016, p. 30, traducción propia).

De entre las variables de insuficiencia de PEHIS 2014 (Pará, 2014), la más alta en número de unidades habitacionales, en las dos ciudades estudiadas se encuentra la falta de infraestructura urbana (Benevides con 12.336 unidades habitacionales y Tomé-Açu con 13.432) (Tabla 1). El PEHIS/2014 también aclara que 
TABLA 1. VARIABLES DE INSUFICIENCIA HABITACIONAL POR UNIDAD HABITACIONAL.

\begin{tabular}{|l|c|c|c|c|}
\hline \multicolumn{1}{|c|}{ Municipios } & $\begin{array}{c}\text { Densificación } \\
\text { excesiva }\end{array}$ & $\begin{array}{c}\text { Falta de } \\
\text { infraestructura }\end{array}$ & $\begin{array}{c}\text { Insuficiencia de la } \\
\text { tierra }\end{array}$ & $\begin{array}{c}\text { Falta de Unidades } \\
\text { Sanitarias Exclusivas } \\
\text { total }\end{array}$ \\
\hline Tomé-Açu & 1.529 & 12.336 & 241 & 1.930 \\
\hline
\end{tabular}

Fuente: Elaboración propia basada en PEHIS/2014 (Pará, 2014).

la insuficiencia debido a la escasez de infraestructura tanto en Benevides como en Tomé-Açu se concentra en la población de ingresos de hasta 03 salarios mínimos.

Como se indica en la introducción de este artículo, con el objetivo de evaluar en qué medida la insuficiencia habitacional por falta de infraestructura urbana fue superada a través del Programa Minha Casa Minha Vida (PMCMV) en el Estado de Pará, se realizó una investigación en dos complejos habitacionales en dos ciudades de Pará, es decir: a) Jardins das Jurutis II con 360 UH entregadas en 2012, en Benevides-PA y; b) Residencial Valle do Ipitinga con 402 UH entregadas en 2015, en Tomé-Açu-PA.

Los hallazgos muestran que la mayoría de las personas entrevistadas en la investigación son mujeres ${ }^{12}$ jóvenes con baja escolaridad (Tabla 2).
En cuanto a la situación socioeconómica de la comunidad residente entrevistada, existe un número significativo de personas desempleadas (Tabla 3). En Benevides, $87 \%$ de la comunidad residente entrevistada tienen de 0 a 2 salarios mínimos, mientras que en Tomé-Açu, este porcentaje llega al 100\%, caracterizando a las familias que viven en pobreza extrema y manteniendo su reproducción social, principalmente, a partir de beneficios sociales y programas de transferencia de ingresos del gobierno federal.

Se puede evidenciar en la investigación el impacto de la crisis económica del capital en la reproducción social de la clase trabajadora, según lo indicado por persona de la comunidad residentes entrevistada "Nadie quiere pagar el pago diario del albañil adecuado, siempre tengo que bajar el precio para no pasar hambre. Ahora este invierno el trabajo se ha

TABLA 2. CARACTERIZACIÓN DE LAS PERSONAS PARTICIPANTES DE LA INVESTIGACIÓN.

\begin{tabular}{|c|c|c|c|c|c|}
\hline Municipio & $\begin{array}{l}\text { Número de Re- } \\
\text { sidentes encues- } \\
\text { tados }\end{array}$ & Sexo & Estado civil & Grupo de edad & Escolarización \\
\hline Benevides & 53 & $\begin{array}{c}\text { Mujeres } \\
(37) \\
\text { Hombres } \\
(16)\end{array}$ & $\begin{array}{c}\text { Solteros (28) } \\
\text { Unión Civil (6) } \\
\text { Casados (15) } \\
\text { Viudo (2) } \\
\text { Divorciado (2) }\end{array}$ & $\begin{array}{l}\text { 18- } 24 \text { años (9) } \\
\text { 25-34 años ( } 7) \\
\text { 35-44 años (17) } \\
45-54 \text { años (9) } \\
\text { 55-69 años (10) } \\
70 \text { o pero (1) }\end{array}$ & $\begin{array}{c}\text { Alfabetización (2) } \\
\text { Enseñanza Primaria incompleta (7) } \\
\text { Enseñanza Primaria completa (3) } \\
\text { Medio incompleto (12) } \\
\text { Promedio completo (22) } \\
\text { Enseñanza Secundaria incompleta (3) } \\
\text { Enseñanza Secundaria completa (2) } \\
\text { Postgrado (2) }\end{array}$ \\
\hline Tomé-Açu & 54 & $\begin{array}{c}\text { Mujeres } \\
(48) \\
\text { Hombres } \\
(6)\end{array}$ & $\begin{array}{c}\text { Solteros (26) } \\
\text { Unión Civil (16) } \\
\text { Casados (12) }\end{array}$ & $\begin{array}{c}\text { 18- } 24 \text { años (10) } \\
\text { 25-34 años (23) } \\
\text { 35-44 años (15) } \\
\text { 45-54 años (2) } \\
\text { 55-69 años (4) }\end{array}$ & $\begin{array}{c}\text { Sin escolaridad (2) } \\
\text { Alfabetización (1) } \\
\text { Enseñanza Primaria incompleta (19) } \\
\text { Enseñanza Primaria completa (4) } \\
\text { Enseñanza Secundaria incompleta (14) } \\
\text { Enseñanza Secundaria completa (13) } \\
\text { Superior incompleto (2) }\end{array}$ \\
\hline
\end{tabular}

Fuente: Elaboración de las autoras, 2019.

12 El artículo 3 de la Ley 11.977, de 7 de julio de 2009, del PMCMV, otorga atención prioritaria a las familias con mujeres responsables de la unidad familiar. 
TABLA 3. TRABAJO E INGRESOS.

\begin{tabular}{|c|c|c|c|c|}
\hline Municipio & Tipo de Trabajo/Ocupación & Ingresos* & Recibir beneficios & $\begin{array}{c}\text { Comercio en el lugar } \\
\text { de residencia }\end{array}$ \\
\hline Benevides & $\begin{array}{c}\text { Desempleados (13) } \\
\text { Funcionario Público (13) } \\
\text { Trabajador autónomo (13) } \\
\text { Trabajo formal (8) } \\
\text { Jubilados (5) } \\
\text { Estudiante (1) }\end{array}$ & $\begin{array}{c}\text { Sin ingresos }(1) \\
\text { Menos de } 1 \text { SM ** (13) } \\
1 \text { a } 2(32) \\
2 \text { a } 3(4) \\
3 \text { a } 5(1) \\
\text { Más de } 6(1) \\
\text { No sé }(1)\end{array}$ & $\begin{array}{c}\text { No recibe (29) } \\
\text { Programa Bolsa Familia } \\
\text { (23) } \\
\text { Beneficio de Prestación } \\
\text { Continua (1) }\end{array}$ & $\begin{array}{l}\text { Sí (10) } \\
\text { No (43) }\end{array}$ \\
\hline Tomé-Açu & $\begin{array}{c}\text { Desempleados (25) } \\
\text { Trabajador autónomo (16) } \\
\text { Funcionario Público (6) } \\
\text { Trabajo formal (4) } \\
\text { Estudiante (2) } \\
\text { Jubilado (1) }\end{array}$ & $\begin{array}{c}\text { Menos de } 1 \text { SM (30) } \\
\text { l a } 2 \text { (24). }\end{array}$ & $\begin{array}{l}\text { Programa Bolsa Familia } \\
\qquad(30) \\
\text { Beneficio de prestación } \\
\text { continua (20); } \\
\text { No recibe (4) }\end{array}$ & $\begin{array}{l}\text { Sí (17) } \\
\text { No (37) }\end{array}$ \\
\hline
\end{tabular}

Fuente: Elaboración de las autoras, 2019. (*) Basado en el salario mínimo. (**) salario mínimo.

ido. Para los que dependen de la agricultura, del trabajo, es demasiado difícil. Aquí vendo carbón que es lo que todavía da porque se vende bien a los vecinos que utilizan horno de leña" (Residente 01- ToméAçu / PA, traducción propia). "A nosotros falta vender las uñas, el pelo, nuestra piel de lo desesperante que es el desempleo. Esperamos la promesa de que haya a una fábrica, de que haya una ocupación para nosotros, pero hasta ahora nada. No quería quedarme en casa, pero incluso para lograr un trabajo para nosotros hay que tener dinero para salir de aquí. Ningún jefe quiere pagar ómnibus para nosotros" (Residente 02- Tomé-Açu /PA, traducción propia).

Se observa que, en general "en la implementación del programa, el lugar de oferta de las UHs no coincide con espacios polarizados para la oferta de empleos" (Cardoso, Aragão, \& Araújo, 2011, p.14, traducción propia), contribuyendo al empobrecimiento aún mayor de las familias que no tienen actividad laboral formal. El discurso de las personas de la comunidad residente nos remite a un pasaje de Marx sobre la acumulación primitiva en la que la clase trabajadora sigue sin tener nada que vender más allá de su fuerza de trabajo: "Fue así que los primeros acumularon riqueza y los últimos terminaron sin nada que vender, sino su propia piel" (Marx, 2013, p. 785, traducción propia).

En cuanto a las reducciones en las tasas de financiamiento de la vivienda en la vida de las personas de la comunidad residente, se observa que hay un impacto en la vida de las familias, que dadas las condiciones de trabajo informal o incluso la falta de trabajo, necesitan garantizar la subsistencia y dejar el pago del financiamiento en segundo plano. Con base en da- tos proporcionados por CAIXA (2019), el porcentaje de contratistas morosos de PMCMV- SECTOR 01 en Benevides es del $76 \%$ de las familias residentes y en Tomé-Açu del 59\% (Tabla 4). En términos empíricos, se debe analizar cuánto la política de vivienda en el Estado de Pará se ha volcado hacia la adquisición de nuevas viviendas a través del financiamiento habitacional en detrimento de acciones que podrían lograr la falta de infraestructura urbana y aspectos de la vida social de las personas residentes que permitan la permanencia o no de estos en los emprendimientos.

En Tomé-Açu solo el 33\% considera el número de cómodos adecuados, esto se debe a que hay familias con un mayor número de miembros, lo que hace que algunos miembros tengan que dormir en otras habitaciones. Según la investigación, $62 \%$ de los encuestados en Benevides consideran una vivienda adecuada. Una de las personas entrevistadas (a) afirma al respecto que: "Ella sí suple, pero si yo pudiera mejorar, yo mejoraría un poco claro, como poner un patio, tirar de una cocina, hacer un poco más grande, aumentar el baño" (Residente 03- Benevides/PA, traducción propia).

De lo contrario, aparece el reconocimiento del significado de la casa, donde "los residentes, incluso ante el alto grado de violencia urbana, registran un sentimiento de paz asociado a la casa, es decir, al aspecto físico/ interno de la vivienda" (Santana \& Perdigão, 2011, p. 09). Como señalan las personas entrevistadas: "No tengo nada de qué quejarme porque aquí tengo mi privacidad, mi libertad [...] Solo quería embaldosar el suelo" (Residente 05 - Benevides/PA). "Mira, [la vivienda] representa todo, cierto, donde que... en mi vida es donde puedo tener dignidad, cierto, para criar a mis 
hijos, y no pagar el alquiler, lo que pago al final será para nosotros incluso, cierto, y eso es todo" (Residente 04 - Benevides / PA, traducción propia).

De entre los principales efectos negativos que el programa trajo a las personas residentes está la desarticulación de las estrategias de supervivencia de las familias. Esto se debe a que, en el lugar de residencia anterior, a pesar de la precariedad de la vivienda, estaba ubicado en zonas rurales, (facilitando el trabajo con el cultivo), zonas urbanas o al margen de esta red urbana, lo que facilitaba la demanda de trabajo, oferta de servicios, venta de productos, etc. Aunque algunos residentes logran utilizar las mismas estrategias de trabajo utilizadas en la empresa, señalan que debido a la gran concentración de familias de bajos ingresos en el lugar, los productos y servicios no son absorbidos.

La investigación mostró que las mejoras de vivienda consisten principalmente en el hecho de que han dejado el alquiler y son dueños de su propia casa, enten- dida como la principal mejora del programa de vivienda (PMCMV). La calidad constructiva de la vivienda también es mencionada como una mejora que, aunque no se considera deseable, la vivienda anterior era muy precaria. Así, a pesar de la mejora en las condiciones de vivienda, las personas entrevistadas destacan la insatisfacción con la baja calidad de los materiales utilizados en la construcción de la vivienda.

Los datos de la investigación muestran que, después de la entrega de unidades habitacionales, al atender, aunque sea mínimamente la necesidad de vivienda, la ejecución del proyecto que acompaña el programa habitacional para proporcionar infraestructura urbana, equipamiento y servicios públicos ${ }^{13}$ queda en un segundo plano. Dado este aspecto es que el $94 \%$ de las personas residentes entrevistadas en Tomé-Açu la consideran mala o muy mala y en Benevides este porcentaje es del $77 \%$. La falta de urbanidad en los complejos habitacionales se refleja directamente en la movilidad urbana de las personas.

TABLA 4. SITUACIÓN DE LA VIVIENDA.

\begin{tabular}{|c|c|c|}
\hline \multirow{2}{*}{ Variables } & \multicolumn{2}{|c|}{ Municipios } \\
\hline & Benevides & Tomé-Açu \\
\hline $\begin{array}{l}\text { Respecto al Pago de la } \\
\text { Mensualidad }\end{array}$ & $\begin{array}{c}\text { Efectúan el pago (30) } \\
\text { Dificultad para realizar el pago (23) }\end{array}$ & $\begin{array}{l}\text { Efectúan el pago (6) } \\
\text { Dificultad para realizar el pago (48) }\end{array}$ \\
\hline $\begin{array}{l}\text { Considera la vivienda adecuada } \\
\text { a las necesidades }\end{array}$ & $\begin{array}{l}\text { Sí (34) } \\
\text { No (19) }\end{array}$ & $\begin{array}{l}\text { Sí (17) } \\
\text { No (37) }\end{array}$ \\
\hline $\begin{array}{l}\text { Número de personas por } \\
\text { propiedad }\end{array}$ & $\begin{array}{l}1(2) \\
2 \text { a } 4(34) \\
5 \text { a } 7(17)\end{array}$ & $\begin{aligned} 1(2) \\
2 \text { a } 4(31) \\
5 \text { a } 7(19) \\
8 \text { a } 10(3)\end{aligned}$ \\
\hline $\begin{array}{l}\text { Principales puntos negativos de } \\
\text { mayor incidencia }^{1}\end{array}$ & $\begin{array}{l}\text { a) Inseguridad; b) la falta de movilidad; c) La falta } \\
\text { de recurso para las reformas; d) Falta de acceso al } \\
\text { esparcimiento; e) Aumento de la tarifa eléctrica. }\end{array}$ & $\begin{array}{l}\text { a) Falta de acceso a los puestos de salud; b) la } \\
\text { falta de movilidad; c) Aumento de la tasa de } \\
\text { energía eléctrica. }\end{array}$ \\
\hline $\begin{array}{l}\text { Principales puntos positivos de } \\
\text { mayor incidencia }\end{array}$ & $\begin{array}{l}\text { a) Posesión de la casa propia; b) Mejora de la rela- } \\
\text { ción familiar; c) Calidad constructiva. }\end{array}$ & $\begin{array}{c}\text { a) Ser propietario de una casa propia y no } \\
\text { pagar el alquiler; b) Disminución de la tasa de } \\
\text { energía; c) Tranquilidad. }\end{array}$ \\
\hline
\end{tabular}

Fuente: Elaboración de las autoras, 2019.

13 Cabe recordar que la aprobación del proyecto solo es posible con la contraparte del municipio para ofrecer infraestructura para el suministro de agua, alcantarillado, electricidad, equipos y servicios públicos.

14 Sin ignorar las particularidades sociohistóricas, es posible verificar a partir de la cita de Engels (2008) las condiciones de la infraestructura de saneamiento en Inglaterra y la tendencia de las condiciones de vida y vivienda para las personas de la clase de trabajadores pobres: "Otros barrios densamente poblados están desprovistos de red de alcantarillado y esto, cuando existe, es insuficiente. En muchas filas de casas, rara vez hay un sótano que no esté húmedo; en muchos barrios, las calles están tomadas por el barro en el que los transeúntes se quedan atascados. Inútilmente los aldeanos buscan mejorarlas, arrojándoles palas de cenizas; sin embargo, el estiércol y las aguas sucias se esparcen frente a las casas hasta que el sol y el viento las sequen y las dispersan" (p. 83, traducción propia). 
Según las entrevistas, la insatisfacción con el alcantarillado considerado malo o muy malo en Benevides es del $47 \%$. Con respecto al saneamiento, hay algunos factores agravantes en Tomé-Açu. Los residentes evalúan el sistema de alcantarillado y exponen que el desperdicio de las unidades habitacionales es pequeño, se llena rápidamente y el servicio de vaciado tiene un alto costo. Dado que la mayoría de los residentes no tienen la condición financiera para solicitar el servicio, dirigen los residuos sólidos y / o líquidos a la calle ${ }^{14}$. También se observó que algunos residentes están construyendo su fosa séptica. Ellos informan que los niños que juegan en la calle son comúnmente diagnosticados con verminosas, micosis, etc. En vista de este escenario, el 89\% de los residentes entrevistados consideran que la red de alcantarillado es mala o muy mala.

\section{TABLA 5. LA RELACIÓN ENTRE PMCMV Y LA SUPERACIÓN DE LA INSUFICIENCIA HABITACIONAL POR IN-} FRAESTRUCTURA URBANA.

\begin{tabular}{|c|c|c|c|c|}
\hline & & Tomé-Açu & Benevides & Síntesis \\
\hline & $\begin{array}{l}\text { Perfil } \\
\text { socioeconómico }\end{array}$ & $\begin{array}{l}\text { Ingresos predominantemente } \\
\text { de } 0 \text { a } 1 \text { salario mínimo. }\end{array}$ & $\begin{array}{l}\text { Predominantemente de } 1 \text { a } \\
2 \text { salarios mínimos. }\end{array}$ & $\begin{array}{l}\text { Se puede decir que hay una aglomeración de per- } \\
\text { sonas en situación de pobreza o extrema pobreza } \\
\text { en los complejos habitacionales. Hay casos muy } \\
\text { puntuales de familias que alcanzan a realizar me- } \\
\text { joras en la unidad habitacional. }\end{array}$ \\
\hline$\stackrel{\mathscr{\Xi}}{=}$ & $\begin{array}{l}\text { Situación de la } \\
\text { vivienda }\end{array}$ & $\begin{array}{l}\text { Unidades habitacionales con } \\
\text { problemas derivados de la } \\
\text { mala calidad constructiva de } \\
\text { las viviendas, infiltraciones, } \\
\text { grietas y alcantarillado. }\end{array}$ & $\begin{array}{l}\text { Unidades con problemas } \\
\text { derivados de la mala ca- } \\
\text { lidad constructiva de las } \\
\text { viviendas, tuberías, alcanta- } \\
\text { rillado sanitario y cableado } \\
\text { eléctrico. }\end{array}$ & $\begin{array}{c}\text { La calidad constructiva de las viviendas es pobre, } \\
\text { aunque consideramos el precario estado de la } \\
\text { vivienda anterior de los sujetos, ya que requiere } \\
\text { sobrecostes de reparaciones y reformas. }\end{array}$ \\
\hline 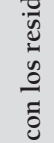 & $\begin{array}{l}\text { Acceso a la } \\
\text { infraestructura }\end{array}$ & $\begin{array}{l}\text { Acceso muy precario. Depen- } \\
\text { dencia del transporte público } \\
\text { (caro y precario). }\end{array}$ & $\begin{array}{l}\text { Acceso parcialmente aten- } \\
\text { dido debido a la presencia } \\
\text { de escuela, unidad básica } \\
\text { de salud, plaza, etc. }\end{array}$ & $\begin{array}{l}\text { Los complejos no cuentan con infraestructura } \\
\text { urbana deseable, de acuerdo con las necesidades } \\
\text { de los residentes. }\end{array}$ \\
\hline 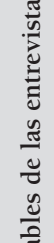 & $\begin{array}{l}\text { Reembolsos de } \\
\text { fondos }\end{array}$ & $\begin{array}{l}\text { El } 89 \% \text { de los residentes tiene } \\
\text { dificultades para pagar la } \\
\text { financiación y tratar directa- } \\
\text { mente con CAIXA para aten- } \\
\text { der esta demanda ya que el } \\
\text { municipio no cuenta con una } \\
\text { secretaría de habitación. }\end{array}$ & $\begin{array}{l}\text { Solo el } 43 \% \text { de los residen- } \\
\text { tes tiene dificultades para } \\
\text { pagar la financiación y la } \\
\text { Secretaría de Habitación se } \\
\text { articula con CAIXA para } \\
\text { recibir estas demandas. }\end{array}$ & $\begin{array}{l}\text { Si consideramos el estatus socioeconómico de los } \\
\text { residentes, se puede afirmar que existe una enor- } \\
\text { me dificultad para pagar la financiación, dada la } \\
\text { condición de desempleo o trabajo informal en la } \\
\text { que viven las familias. }\end{array}$ \\
\hline 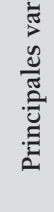 & $\begin{array}{l}\text { Participación } \\
\text { social }\end{array}$ & $\begin{array}{c}\text { No se identificaron procesos } \\
\text { de participación social. }\end{array}$ & $\begin{array}{c}\text { A pesar de la fragmenta- } \\
\text { ción, existe una asociación } \\
\text { de vecinos que luchan } \\
\text { constantemente por algu- } \\
\text { nas mejoras en el complejo } \\
\text { habitacional. }\end{array}$ & $\begin{array}{l}\text { Hay poca o ninguna participación social, motiva- } \\
\text { da, según los vecinos, por la coacción del gobier- } \\
\text { no municipal o incluso por la falta de expectati- } \\
\text { vas de que la lucha se revertirá en la garantía de } \\
\text { los derechos de los residentes. }\end{array}$ \\
\hline & $\begin{array}{l}\text { PMCMV y } \\
\text { superación de } \\
\text { la insuficiencia } \\
\text { por } \\
\text { infraestructura } \\
\text { urbana }\end{array}$ & $\begin{array}{l}\text { El programa superó el déficit } \\
\text { de vivienda, pero no superó } \\
\text { la insuficiencia de la falta de } \\
\text { infraestructura urbana. }\end{array}$ & $\begin{array}{l}\text { El programa superó el défi- } \\
\text { cit de vivienda, pero superó } \\
\text { parcialmente la insuficien- } \\
\text { cia por la infraestructura } \\
\text { urbana. }\end{array}$ & $\begin{array}{l}\text { En resumen, se puede afirmar que el Programa } \\
\text { contribuyó a superar el sinhogarismo. Sin em- } \\
\text { bargo, no superó la insuficiencia habitacional por } \\
\text { infraestructura urbana, una vez que la entrega de } \\
\text { unidades habitacionales no fue acompañada por } \\
\text { la entrega de estos servicios, por lo que los resi- } \\
\text { dentes tuvieran que restablecer nuevas relaciones } \\
\text { sociales con el espacio urbano o incluso seguir la } \\
\text { rutina de relaciones ya establecidas con el centro } \\
\text { de la ciudad. En las situaciones más graves, la } \\
\text { aceptación del aislamiento impuesto por el lugar. }\end{array}$ \\
\hline
\end{tabular}

Fuente: Elaboración de las autoras. (Solicitud de formularios y entrevistas con residentes), 2019. 
TABLA 6. RESUMEN DE LAS ENTREVISTAS.

\begin{tabular}{|c|c|}
\hline Variables de las entrevistas & Síntesis \\
\hline Perfil socioeconómico & $\begin{array}{c}\text { División social y técnica del trabajo es determinante para los ingresos de las familias, donde Benevides } \\
\text { concentra a las familias con ingresos de } 01 \text { a } 02 \text { salarios mínimos y Tomé-Açu las familias sin ingresos o } \\
\text { con ingresos inferiores a } 01 \text { salario mínimo. }\end{array}$ \\
\hline Situación de la vivienda & $\begin{array}{l}\text { Carecen de habitaciones más grandes y ventiladas además de las condiciones para llevar a cabo repara- } \\
\text { ciones en la estructura interna de la casa, así como externa (con destaque para el alcantarillado). }\end{array}$ \\
\hline $\begin{array}{l}\text { Acceso a la infraestructura y a } \\
\text { los servicios públicos }\end{array}$ & $\begin{array}{c}\text { El acceso a la infraestructura urbana y a los servicios públicos en la empresa es precario, ya sea por la } \\
\text { falta total de esta cobertura o por la falta de pertenencia al uso de estos espacios que, por ser entrega- } \\
\text { dos tras años de espera, los vecinos terminan construyendo sus propias formas de su de suministro de } \\
\text { necesidades. }\end{array}$ \\
\hline $\begin{array}{l}\text { Impactos de la financiación } \\
\text { de la vivienda }\end{array}$ & $\begin{array}{l}\text { Existen impactos de financiación de la vivienda en la vida de las familias, que se expresan ya sea pagan- } \\
\text { do con dificultades o por impago, concentrando a un número importante de familias morosas (es decir, } \\
\text { no pueden pagar las cuotas mensuales previstas en el Programa). }\end{array}$ \\
\hline Participación social & La participación social en torno al PMCMV sigue siendo un desafío; 2) Inexistente. \\
\hline $\begin{array}{l}\text { PMCMV y superación } \\
\text { de la insuficiencia por } \\
\text { infraestructura urbana }\end{array}$ & En definitiva, poco o nada se supera la insuficiencia por la falta de infraestructura urbana. \\
\hline
\end{tabular}

Fuente: Elaboración de las autoras (Solicitud de formularios y entrevistas con residentes), 2019.

Las Tablas 5 y 6 resumen los principales hallazgos de la investigación, a partir de las variables investigadas sobre el tema de la insuficiencia habitacional relacionada con la implementación del Programa "Minha Casa Minha Vida".

Los derechos declarados por la ley, como el derecho a la vivienda y a la ciudad, sólo son aplicables a través de políticas públicas, que, a su vez, son operativas a través de programas, proyectos y servicios (Behring \& Boschetti, 2006). De ahí la importancia de estimular la participación y la organización social y política de los sujetos para luchar por objetivos comunes.

La investigación mostró que el programa MCMV presenta una contradicción: al mismo tiempo que contribuye a la reducción del déficit habitacional y promueve el derecho a la vivienda para la población de menores ingresos, no satisface otras necesidades de vivienda, como el tema de la infraestructura. En este sentido, el vecino del municipio de Tomé-Açu señala que:
Tenía mi derecho garantizado con el programa. No hay liderazgo de nada, no hay centro de salud, no hay agente de salud, no hay dengue. No hay nada en él. Cualquiera que necesite algo tiene que salir a Quatro-Bocas o Tomé-Açu. La escuela que tenía allí ya no funciona porque aumentaron el alquiler y la ciudad dejó de pagar. Solo había movimiento en la época de la política, el centro comunitario vivía lleno porque los políticos hicieron mil promesas, pero, después de que pasó, abandonaron. Yo he pensado en entrar en esto, pero lo que quiero es estar tranquilo (Residente 07, traducción propia).

Los vecinos, por no concebir la recepción de vivienda como un derecho, terminan naturalizando el hecho de que la unidad es de mala calidad, en el sentido de que, si "La Casa es Popular, iqué esperaba?" (Ferreira, \& Freire, 2015, p. 01, traducción propia). Como señala un residente de Tomé-Açu entrevistado "tenemos que agradecer claro, fue Dios quien nos dio esta casa" (Residente 06, traducción propia). 
[...] Al vincular la satisfacción de las necesidades sociales a través de medidas de crecimiento económico, el Estado sirve a los intereses del mercado inmobiliario, provoca la pasivación de los movimientos sociales urbanos y descalifica al SNHIS ${ }^{15}$ como mecanismo de acceso a la vivienda [...] (Abreu, 2015, p. 132, traducción propia).

Así, la desmovilización se convierte en un obstáculo para el alcance de las estrategias, tanto en el contexto de la supervisión de las obras del Programa MCMV, como para una organización social de trabajadores que busca reflexionar y cuestionar los problemas derivados del programa de vivienda. De esta manera, es necesario "[...] construir proyectos para combatir la fragmentación y homogeneización del espacio por el capital [...]" (Abreu, 2015, p. 135, traducción propia), rescatando la ciudad como lugar de lucha de clases.

Así, se reafirman las contradicciones de la lógica del capital y la selectividad de los espacios que tendrán infraestructura en las ciudades estructuradas para satisfacer los intereses de las empresas capitalistas, mediadas por la acción del Estado.

Sobre los impactos de las tasas de financiamiento de la vivienda en la vida de los residentes, se observa que, a pesar de ser un valor simbólico considerable de bajo costo, afecta la vida de las familias, que dadas las condiciones de trabajo informal o incluso la falta de trabajo, necesitan garantizar la subsistencia y dejar el pago de fondos en segundo plano.

La lógica de mercado que asume el programa de vivienda ha traído reflexiones sobre el espacio urbano respecto a su potencial para reducir o no las desigualdades socioespaciales y que demandan una comprensión del lugar que ocupa la Amazonía en la división socio territorial del trabajo, ya que la dinámica social es penetrada por varios procesos de expropiación. Así, la dimensión territorial y los medios de vida locales no impiden la expansión del capital en la Amazonía, vez que "[...] la tendencia histórica del capitalismo es destruir y absorber los modos de producción no capitalistas [...]" (Harvey, 2005, p. 58, traducción propia).

Así, están los elementos para entender hasta qué punto se niega la garantía del derecho a vivienda en la Amazonía a través del tema de la pose de la tierra, puesto que el acceso a la tierra urbanizada está condicionado a la lógica financiera de la producción de vivienda, renovando viejas formas de expropiación de trabajadores.

Por lo tanto, Sakatauskas, Santana y Leitão (2018) analizan las particularidades regionales de la Amazonía y la producción de vivienda en estudio sobre la precariedad habitacional en ocho pequeñas ciudades de Pará (Aveiro, Anapu, São José do Porfírio, Curionópolis, Eldorado dos Carajás, São João do Araguaia, Faro y Placas), concluyendo que la precariedad de la infraestructura está muy presente, así como el alto índice de pobreza. En el mismo sentido, Costa y Santana (2017) encontraron que en cinco pequeñas ciudades de la Amazonía: Aurora do Pará, Limoeiro do Ajuru, Primavera, São Francisco do Pará y Soure, se verifica la importancia de los instrumentos de vivienda de interés social, aunque estén en un segundo plano frente a la implementación del PMCMV. El programa presenta retraso de obras, falta de diálogo del municipio con instituciones financieras y uso de materiales con poca calidad en la producción de vivienda, así como no considera la particularidad regional de la Amazonía.

La Amazonía tiene así particularidades que conforman aspectos culturales, políticos e ideológicos, que retratan la experiencia de quienes las construyen (Oliveira, 1999). Esta construcción enfrenta varios sujetos sociales, de entre ellos el capital, que subvierte la vida social de los trabajadores al transformar la tierra y la vivienda en mercancías, es decir, "las transformaciones del espacio urbano amazónico se deben a los diversos conflictos y tensiones sociales derivadas de las contradicciones entre el capital y el trabajo" (Melo, \& Santana, 2018, p.03, traducción propia).

En ambos municipios encuestados, existe la necesidad de una gran cocina y patio en la UH. Este campo de análisis fue estudiado por Perdigão y Gayoso da Costa (2012) enfatizando las relaciones que existen entre el espacio residente y físico de la vivienda, interpretado por la casa como institución social y lugar. En términos generales, la casa como institución social se entiende "como un lugar especulativo de la estructura socio-cómica e institucional de la sociedad" (Perdigão $\&$ Gayoso da Costa, 2012, p.118), es decir, es el lugar de organización familiar. Si bien la casa como lugar es considerada un reto, se puede decir que está ligada al espacio vivido, construido, producido y reproducido, como un espacio dotado de valor. Por lo tanto, es importante entender la casa en su totalidad porque compone varias dimensiones de la vida social y cultural de los sujetos. 
En este análisis, se opta por considerar el análisis de la casa como un lugar vinculado al concepto de espacio vivido. Carlos (2007) entiende que el lugar es la producción humana construida a través de la relación entre el espacio y la sociedad, es el espacio apropiado para la vida social, "[...] lugar es el mundo de lo vivido, es donde se formulan los problemas de producción en sentido amplio, es decir, la forma en que se produce la existencia social de los seres humanos" (Carlos, 2007, p. 20, traducción propia). Para Milton Santos (2014), el lugar es, a su manera, el mundo, porque dialécticamente incluye las relaciones de los sujetos sociales entre el tiempo y el espacio que ahora se individualizan, colectivizan, armonizan, o entran en conflicto.

El lugar absorbe las influencias de la reproducción social y económica, pero también las relacionadas con la vida cotidiana de la vida social. Se puede decir entonces que la necesidad señalada por los sujetos de la investigación de tener un patio y una cocina más grandes expresa una relación sociocultural históricamente construida sobre la relación entre sujeto-sujeto, sujeto-espacio en las casas de la región amazónica, particularmente en el estado de Pará. El acto de reunirse en estos espacios de convivencia social produce significados y significados históricamente tejidos.

La importancia de la vivienda como lugar debe considerar que "[...] la percepción del lugar donde vive, como singularidad y territorio de subjetividad es, al mismo tiempo, identificada como un lugar singular/universal de la condición humana [...]" (Castro, 2011, p. 16, traducción propia).

La estandarización de UH se torna un problema para las familias, porque la casa no está adaptada a la cultura amazónica, siendo necesario hacer algunos cambios externos como la creación de estufas de leña al aire libre, jirau ${ }^{16}$ y el cultivo de huertos, considerados como componentes culturales muy fuertes de la forma de vivir y habitar en el Amazonas.

Como afirma un entrevistado: "Cuando vinimos aquí, esto era solo pared y techo, no era realmente una casa. Luego tuve que mudarme, como soy albañil ya he hecho fosa, he hecho esta zona para aumentar la cocina porque hacía demasiado calor" (Residente 04Tomé-Açu /PA, traducción propia).
En cuanto a la comprensión de lo que constituye la insuficiencia habitacional para los residentes que recibieron sus viviendas del PMCMV, se verifica que, a pesar de la satisfacción de los residentes por la pose de su propia vivienda, existen condiciones más generales de habitabilidad que no son cumplidas por el programa de vivienda. Los residentes entienden que para que una condición de vivienda sea adecuada, es necesario favorecer la permanencia, el uso y el sentido de pertenencia, es decir, garantizar el servicio de agua, energía, alcantarillado, seguridad, salud, educación, ocio, accesibilidad, movilidad y especialmente al trabajo.

En este sentido, se puede inferir que el PMCMV no supera las tasas de insuficiencia habitacional en las dos pequeñas ciudades estudiadas y reproduce la tendencia histórica de provisión habitacional para la población de menores ingresos al concentrar la pobreza y no proporcionar las condiciones necesarias para el mantenimiento de la vida y la vivienda en complejos habitacionales. Hay entonces un abismo de desigualdades sociales en la que en las ciudades encuestadas uno se expresa por la pobreza extrema que marca la formación sociohistórica de la Amazonía y de su inserción de la división social del trabajo.

\section{Conclusiones}

Los obstáculos relacionados con la cuestión de la vivienda no son recientes, mientras que la constitución sociohistórica de las ciudades en Brasil ocurrió desde el período colonial y dirigió a los trabajadores esclavos a las condiciones de vida y vivienda más deplorables. A partir de la formación de las ciudades, se verifica que su producción está constantemente impregnada por los intereses capitalistas en la búsqueda de la valorización y acumulación ininterrumpida de capital. Frente a este predominio del capital sobre la producción de las ciudades y la vivienda se está reproduciendo desigualdades sociales que hacen aún más claras las divisiones y los conflictos de clases.

Por lo tanto, la dualidad adecuación/insuficiencia tiene como parámetro central la premisa de que para alcanzar las necesidades de vivienda es necesario contar con condiciones deseables de habitabilidad que aseguren a los sujetos y a sus familiares, bienestar, seguri-

16 Consiste en la construcción de fregadero de madera, generalmente muy ancho, no solo para lavar platos, sino también para tratar alimentos. Por lo general, está cerca de la estufa de leña (utilizado para una cuestión cultural, pero también como una estrategia frente al alto costo de las bombonas de gas) y en el curso del flujo de su agua hay la plantación de algunas plantas frutales. 
dad, salud, es decir, condiciones para su reproducción social.

Lo que sucede con la formación contradictoria de las ciudades es un abismo de desigualdades, típica del proceso de acumulación capitalista, que históricamente delega a la población de menores ingresos los lugares que no tienen estas condiciones deseables de habitabilidad, con especial atención a la falta de infraestructura urbana. Así, el Estado, cuando promueve el acceso a los derechos sociales de vivienda, reproduce la lógica del modo de producción que garantiza el derecho a la vivienda como estructura física, o como señala Borges (2017, traducción propia), la vivienda de interés social garantiza azulejos y ladrillos, negando el acceso al hogar, la vivienda en su sentido más completo de garantía de los derechos sociales. Esto se debe a que, en el plano inmediato, la casa aparece sólo como un objeto físico y geométrico, compuesto por materiales de construcción como vigas, ladrillos, lienzos, madera, etc. (Gayoso da Costa \& Perdigão, 2012).

Así, los datos presentados indican que la producción de vivienda a través del Programa "Minha Casa Minha Vida" no contribuye a superar la insuficiencia habitacional por infraestructura urbana, ya que la entrega de unidades habitacionales se limita únicamente a la entrega de unidades de vivienda, las cuales no van acompañadas de la infraestructura urbana necesaria para el mantenimiento de la vida social y permanencia de las familias en el lugar elegido por el gobierno para albergar la empresa.

Aun cuando el complejo habitacional cuenta con infraestructura urbana, su entrega a la población está permeada por la lentitud que lleva a las personas residentes a construir otras relaciones sociales con el espacio urbano. Es evidente la falta de pertenencia y uso de los espacios públicos en los emprendimientos, justificada por las relaciones ya construidas con el centro de la ciudad que cuenta con mejores infraestructuras y servicios.

La investigación sobre planes locales de vivienda de interés social/PLHIS constataron que la mayor insuficiencia habitacional en las ciudades de Pará es la infraestructura en el suministro de agua y el alcantarillado (Melo, 2017; Costa \& Santana, 2017). De este estudio se puede inferir que esta insuficiencia permanece en las ciudades, afectando la calidad de vida y la salud de las personas residentes de manera consustancial.
Se considera entonces que la insuficiencia habitacional, además de perjudicar la calidad de vida por la falta de condiciones de vida deseables, provoca un aumento en el costo de vida, porque las familias necesitan satisfacer sus necesidades, ya sea que tengan acceso a transporte alternativo, acceso a ferias y mercados, reformas de fosas y reparaciones en general en la vivienda.

El PMCMV, a pesar de proporcionar viviendas populares de bajo costo, promueve consustancialmente transformaciones en la estructura de las relaciones capitalistas de producción, ya que permite que la fracción más empobrecida de la clase trabajadora adquiera parte de la propiedad privada de la tierra. Sin embargo, alimenta en mayor proporción el modo de producción capitalista, ya que la vivienda como mercancía forma parte de la lógica especulativa e inmobiliaria, adquiriendo mayor valor que el primero al inicio del proceso productivo (Ramos, 2008) contribuyendo a la inserción de familias de bajos ingresos en los procesos de financiación y endeudamiento.

Una tendencia basada en la particularidad del proceso de acumulación de capital, que tiene como impulso vital auto valorar y extraer valor agregado a través de la explotación del trabajo, produciendo y reproduciendo la pobreza y miseria de los trabajadores. De este modo, las determinaciones más generales de la Ley General de Acumulación son vistas como el núcleo de la cuestión de la vivienda, porque el trabajador, ante la necesidad de vender su mano de obra para sobrevivir, acaba supliendo la necesidad de vivienda de la manera que le es posible.

Frente a la compleja realidad que se impone como un desafío de análisis del tema urbano y de vivienda para la clase trabajadora, es necesario permitir el acceso a su propia casa a través de los principios de justicia social y parámetros relacionados con la vivienda y las necesidades habitacionales y humanas, así como construir colectivamente estrategias para combatir la despolitización y el avance del capital sobre el espacio urbano (Abreu, 2015).

El PMCMV se distancia no sólo de los parámetros de la política de vivienda de interés social, sino también de los parámetros de adecuación de la vivienda, que, cuando están directamente vinculados a las necesidades sociales y los principios de justicia social, son históricas, objetivas y universales, y aborda la asistencia respecto a la vivienda con vistas a la to- 
talidad, teniendo en cuenta las particularidades regionales, la cobertura de la infraestructura urbana y los servicios, alternativas a la generación de empleo e ingresos, áreas que podrían contribuir a la realización del derecho a la vivienda en las pequeñas ciudades de Pará.

Así, la política urbana y habitacional brasileña se formuló no solamente para proporcionar un techo, sino para suplir una alta tasa de déficit habitacional como una demanda de la clase trabajadora a través de la organización política. Con la creación del Programa "Minha Casa Minha Vida" y su carácter explícito de mercado, el PMCMV permite el acceso a una vivienda y no las condiciones básicas de supervivencia para que las familias se queden en los proyectos habitacionales, tales como trabajo, renta, seguridad, saneamiento básico, movilidad, entre otros.

Así, se verifica que las contribuciones teóricas de la categoría profesional de trabajadores sociales (y no sólo de esta), planteadas en el proceso de construcción del estado del arte del objeto a través de la investigación bibliográfica para el tema de la vivienda brasileña, tuvieron como hilo conductor el materialismo histórico y dialéctico. Por otra parte, el estado del arte realizado para la construcción de este estudio apunta a la contradicción de la política de vivienda social, que se expresa en la exclusividad del PMCMV en Brasil, que se puede inferir como intencionada, una vez que garantiza el acceso a la vivienda para la población de menores ingresos y, a la vez, promueve una inserción del mercado inmobiliario con la proliferación de bancos privados que gestionan programas de vivienda y organizan estrategias para abaratar los costos de producción, lo que trae consecuencias devastadoras para la calidad de las obras, terrenos lejanos, entre otros.

Es importante fijar que en el contexto de las demandas y respuestas profesionales en la política urbana y de vivienda, es esencial que la categoría profesional de Trabajadores Sociales realice investigaciones guiadas por el proyecto ético político de la profesión y cuya investigación pueda apoyar un trabajo comprometido con la clase trabajadora y con la elaboración de estrategias de lucha y resistencia al derecho a la vivienda y a la ciudad (Melo \& Santana, 2018).

Ante esto, enfatizamos la importancia de fortalecer las bases teórico-metodológicas, ético-políticas y técnicooperativas del trabajo social, para que no haya despoli- tización del hacer profesional (Gomes, 2015) y especialmente para posibilitar el alcance de las determinaciones del tema de la vivienda, descartándose la realidad y buscando estrategias para superar la condición de subalternidad que enfrentan las familias que buscan alternativas cotidianas a la necesidad de vivienda. Se verifica la vinculación del Trabajo Social con los procesos de formulación, gestión y ejecución de las políticas sociales como profesión insertada en la división sociotécnica del trabajo y comprometida con un proyecto corporativo para superar las desigualdades sociales a través de la supresión del modo de producción capitalista.

\section{Referencias}

ABREU, A. (7 noviembre de 2015). Disputa de projeto: a reforma urbana e os movimentos sociais. Revista Ser Social. 17, n. 36, p. 124. https://periodicos.unb.br/index.php/SER_Social/article/view/13419/11747.

ARAGÃo, T. (2015). O Programa Minha Casa Minha Vida: uma avaliação do modelo de políticas de quasemercado. In. XVI ENANPUR: Espaço, planejamento e insurgências. Belo Horizonte.

ARANTES, P. Y FIX, M. (30 de julio de 2009) Como o governo Lula pretende resolver o problema da habitação: Alguns comentários sobre o pacote habitacional Minha Casa, Minha Vida. Correio da Cidadania, São Paulo-SP. https://www.correiocidadania.com.br/especiais/66pacote-habitacional/3580-31-07-2009-minha-casa-minha-vida-o-pacote-habitacional-de-lula.

BEHRING, E. Y BOSCHETTI, I. (2006). Política Social: fundamentos e história. - São Paulo: Cortez.

BORGES, A. (2017). Minha Casa, Minha Vida, Meu Lar. Será mesmo? Uma visão sobre as recentes políticas habitacionais de interesse social e suas ações além das telhas e tijolos. [Disertación de maestría, Universidade Federal do Rio Grande do Sul]. https://lume.ufrgs.br/ handle/10183/178410.

CAIXA ECONÔMICA FEDERAL [CAIXA]. MINHA CASA MINHA VIDA- HABITAÇÃO URBANA. http://www.caixa.gov.br/voce/habitacao/minha-casaminha-vida/urbana/Paginas/default.aspx Acceso em: 07 de Janeiro de 2019.

CARDOSO, A. Y ARAGÃO, T. Y ARAÚJO, F. (25 de noviembre de 2011). Habitação de interesse social: política ou mercado? Reflexos sobre a construção do espaço metropolitano. Encontro Nacional Da Associação Nacional De Programas De Pós-Graduação E Pesquisa Em Planejamento Urbano E Regional, XIV, Rio de JaneiroRJ. https://anais.anpur.org.br/index.php/anaisenanpur/ article/view/683/669 
CARDOSO, A. Y ARAGÃO, T. (2013). Do fim do BNH ao Programa Minha Casa Minha Vida: 25 anos da política habitacional no Brasil. Cardoso, A.L. (Org.) O Programa Minha Casa Minha vida e seus efeitos territoriais. 1. Ed. Rio de Janeiro: Letra Capital. https:// observatoriodasmetropoles.net.br/arquivos/biblioteca/ abook_file/mcmv_adauto2013.pdf.

CARDOSO, A. Y JAENISCH, S. (septiembre de 2014) Nova política, velhos desafios: problematizações sobre a implementação do programa Minha Casa Minha Vida na região metropolitana do Rio de Janeiro. e-metrópolis: Revista eletrônica de Estudos Urbanos e Regionais, v. 5, p. 6-19, http://emetropolis.net/system/edicoes/ arquivo_pdfs/000/000/018/original/emetropolis_n18. pdf? 1447896374.

CARLOS, A. (2007) O lugar no/do mundo. São Paulo: FFLCH. https://gesp.fflch.usp.br/sites/gesp.fflch.usp. br/files/O_lugar_no_do_mundo.pdf

COSTA, N. Y SANTANA, J. (09 de ouctubre de 2017). Produção habitacional em pequenas cidades paraenses: análise do Programa Minha Casa Minha Vida e Planos Locais de Habitação de Interesse Social. Revista Sociedade em debate, v. 23, p. 195-231. https://revistas.ucpel.edu.br/rsd/article/view/1588/1049.

CASTRO, E. PREFÁCIO. (2011). Políticas Públicas e lutas sociais na Amazônia: enfoques sobre planejamento gestão e territorialidade. Santana, J y Sá M. - Belém: ICSA/UFPA.

ENGELS, F. (2008). A situação da classe trabalhadora na Inglaterra. - São Paulo: Boitempo. https://edisciplinas. usp.br/pluginfile.php/4662435/mod_resource/content/1/ENGELS.pdf

ENGELS, F. (2015). A questão da habitação. - São Paulo: Boitempo.

FERREIRA, B. Y SANTANA, J. (31 de agosto de 2018) A dialética conhecimento/transformação do mundo no legado marxista. Revista Argumentum, Vitória ES, v. 10, n.2, p.70-83. https://periodicos.ufes.br/argumentum/article/view/19534/14165

FERREIRA, D. Y FREIRE, J. (2015) "A casa é popular, esperava o quê?": sentidos da habitação popular no quadro do Programa Minha Casa, Minha Vida. En: XVI Enanpur, Belo Horizonte-MG

GOMES, M. (27-21 de julio de 2015). Trajetória histórica do Serviço Social e políticas urbanas- retorno à práticas de apoio à remoção de moradores de favelas? Anais do XXVIII Simpósio Nacional de História: lugares dos historiadores: velhos e novos desafios. Florianópolis - SC. http://www.snh2015.anpuh.org/resources/ anais/39/1427799038_ARQUIVO_SimposioNacionaldeHistoria2015.pdf.

HARVEY, D. (2005). A produção capitalista do espaço. - São Paulo: Annablume. http://www.mom.arq.ufmg br/mom/02_babel/textos/harvey-producao-capitalistaespaco.pdf

INSTITUTO BRASILEIRO DE GEOGRAFIA E ESTATÍSTICA [IBGE]. (2017). Mapa político da região Norte.https://geoftp.ibge.gov.br/cartas_e_mapas/mapas_regionais/politico/2017/norte_politico2700k_2017.pdf.

MARX, K. (2013). O capital: crítica da economia política. Livro I. São Paulo: Boitempo. https://edisciplinas.usp. br/pluginfile.php/2547757/mod_resource/content/1/ MARX\%2C\%20Karl.\%200\%20Capital.\%20vol\%20 I.\%20Boitempo.pdf

MELO, M. A produção habitacional por meio do Programa Minha Casa Minha Vida em pequenos municípios paraenses. (2017) [Monografía, Universidad Federal do Pará). Belém-PA.

MELO, M. Y SANTANA, J. (08 de octubre de 2018). A produção habitacional em pequenos municípios da Amazônia. Revista Libertas, Juiz de Fora, v.18, n.1, p. 01-26, jan. a jul. /https://periodicos.ufjf.br/index.php/ libertas/article/view/18567/9711

OLIVEIRA, J. (1999). As pequenas cidades da Amazônia: espaços perdidos e reencontrados. O Espaço no fim do século: a nova raridade. (Org.). Amélia Damiani, Ana Carlos, Odette Seabra. - São Paulo: Contexto.

PARÁ (2014). Síntese e atualização do Plano Estadual de Habitação de Interesse Social (PEHIS). http://www.cohab. pa.gov.br/sites/default/files/PEHIS_S\%C3\%ADntese\%20 e\%20Atualiza\%C3\%A7\%C3\%A3o_Nov_2014.pdf

PAZ, R.; ARREGUI, C.; BLANCO, M.; RODRIGUES, M.; TABOADA, K. (2018) Trabalho Social na Política Habitacional: percursos, lacuna e desafios. Santana, J. Habitação e Serviço Social: dimensões teóricas, históricas e metodológicas. Ed Papel Social: Campinas.

PERDIGÃO, A. K.; GAYOSO DA COSTA, S. (2012). Interpretações sobre a casa para a produção de moradia. Santana, J.; Holanda, A.; Moura, A. A questão da habitação em municípios periurbanos na Amazônia. led.Belém: EDUFPA, v. 1, p. 1-398.

RAMOS, M. (2008). Habitação, um meio de reprodução social. Gomes, M.; Fernandes, L.; Maia, R. Interlocuções Urbanas: cenário, enredo e atores. 0led. Rio de Janeiro: Arco Iris, v. 01, p. 197-216.

RAMOS, M.; SÁ, M. (2002). Avaliação da política habitacional popular segundo critérios de eficácia societal. Metamorfoses sociais e Políticas Urbanas. RAMOS, M. - Rio de Janeiro: Ed: DP\&A.

ROLNIK, R. (2015). Guerra dos Lugares: a colonização da terra e da moradia na era das finanças. - 1 ed. - São Paulo: Boitempo.

SAKATAUSKAS, G., SANTANA, J. Y LEITÃO, K. (2018) Precariedade habitacional em pequenos municípios paraenses. Revista $\mathrm{O}$ social em questão. v. 21, p. 
23-44, 2018. http://osocialemquestao.ser.puc-rio.br/ media/OSQ_42_SL_3.pdf.

SANTANA, J. Y FERREIRA, B. (2021). Crise do capital e impacto da covid-19 na vida dos trabalhadores: desigualdades socioterritoriais na periferia e em regiões do Brasil. Revista O Social em Questão - Ano XXIV - no 49 - Jan a Abr/2021. pp. 123-148. https://www.maxwell. vrac.puc-rio.br/51117/51117.PDF.

SANTANA, J. Y HOLANDA, A. (2016). Reflexões acerca da carência habitacional no Pará: dados comparativos entre os anos 2000 e 2010. O avesso dos direitos: Amazônia e Nordeste em questão II. Editora Universitária, UFPE: Recife.
SANTANA, J. Y PERDIGAO, A. (2011). Participação dos moradores na produção habitacional: análise da área CDP (Belém-Pará-Brasil).X Congreso Argentino de Antropología Social. Editorial de la Facultad de Filosofía y Letras, Universidad de Buenos Aires.

SANTOS, M. (2014). A natureza do espaço. - 4. Ed. São Paulo: USP.

SHIMBO, L. (2010). Habitação Social, Habitação de Mercado: a confluência entre Estado, empresas construtoras e capital financeiro. [Tesis de Doctorado, Universidad de Sao Paulo]. https://www.teses.usp.br/teses/ disponiveis/18/18142/tde-04082010100137/publico/ tese_lucia_shimbo_jun10_final.pdf. 